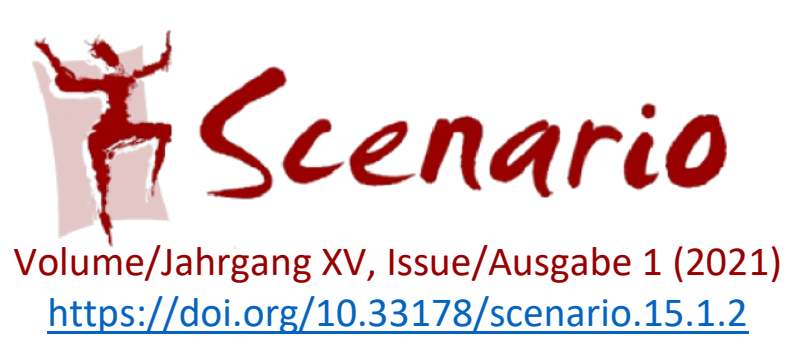

\title{
Shared Experiences
}

\section{A performative approach to intercultural education}

\author{
John Crutchfield
}

During the academic year 2018-2019, the Department of Languages and Literatures at the University of the North Carolina - Asheville (UNCA) launched a pilot curriculum in Intercultural Education for intermediate-level foreign language students in French, Spanish and German. It was decided early on to adopt a performative/experiential approach, and to accompany the project with an empirical study based on qualitative data. This article lays out the parameters, contexts and challenges of the project itself and summarizes the findings of the accompanying study, including an articulation of questions that remain for future exploration.

\section{Institutional context}

At a recent academic conference, Manfred Schewe, perhaps the leading exponent of performative foreign language pedagogy since the 1990's, remarked upon the crucial importance of context in how we imagine good teaching. That admonition is certainly relevant to this study. Every aspect of teaching, from curricular design to pedagogical implementation to assessment, is context-specific, and yet "context" itself is a notoriously complex synthesis of factors, not all of which are susceptible to description. The best one can do is to strive for transparency and to describe as fully as possible what can be described. In what follows, I will attempt to elucidate the specific context of our work as my colleagues and I have come to know it. My hope is that such specificity will make it easier for others to adjust our findings to their own specific contexts, and perhaps even to distill from them a more general applicability.

The University of North Carolina at Asheville is a small public university located in rural Southern Appalachia, a part of the United States that, though rich in natural resources, has been historically poor. ${ }^{1}$ At the same time, UNCA is also "[t]he only dedicated liberal arts institution in the University of North Carolina system." ${ }^{2}$ This produces an unusual set of circumstances for teaching. With well under 4000 students at last count, UNCA is able to offer

\footnotetext{
${ }^{1}$ As of 1960 , one in three Appalachians lived in poverty, per capita income was $23 \%$ lower than the U.S. average, and high unemployment and harsh living conditions had forced more than 2 million Appalachians to leave their homes and seek work in other regions. This state of affairs prompted Presidents John F. Kennedy and Lyndon B. Johnson to form the Appalachian Regional Commission "to address the persistent poverty and growing economic despair of the Appalachian Region." https://www.arc.gov/index.asp

${ }^{2}$ https://www.unca.edu/
} 
small-sized classes (20 students on average) taught by trained faculty rather than, for example, by graduate assistants. Of these students, only $12 \%$ are self-identified "minorities" and a mere $1 \%$ are "internationals" (non-U.S. citizens). The typical UNCA student is white, from North Carolina, a first-generation college student, a recipient of financial aide, and a virtual tabula rasa in terms of personal experience abroad or even of substantive interactions with other cultures at home. ${ }^{3}$ This means that, for most of our students, the two semesters of beginning FL study required for graduation are not only the "most important zone for 'rehearsing' these exchanges" (Crutchfield \& Schewe, 2017, p. xiii) but likely the only such zone they will ever know. Given the explicit liberal arts emphasis of the University, this places a significant responsibility on the FL faculty, a responsibility that goes well beyond merely teaching the rudiments of a foreign language. We are also responsible for teaching the rudiments of interculturality and intercultural competence.

An important departmental context should be mentioned here as well. In 2017, and in response to a variety of institutional challenges, the Department of Languages and Literatures decided to combine what had previously been separate academic majors in Spanish, French and German into a single major with concentrations offered in those languages, including new curricula in Portuguese and Cherokee. ${ }^{4}$ This raised the question of whether a major in Languages and Literatures shouldn't also involve a certain core curriculum common to all concentrations. The discussions surrounding this question gave rise in turn to the mandate for the pilot program described below. The Shared Experiences as they came to be called, were imagined as "interactive workshops meant to create a community of language learners and to broaden our understanding of what it means to study languages and literatures" ${ }^{5}$. Among the topics to be covered were "cultural competency and cultural appropriation, as well as global issues that impact peoples of all national origin, such as the treatment of our natural

\footnotetext{
${ }^{3}$ While most entering $1^{\text {st }}$-year students will have had some exposure to foreign language study in high school, few are able to "place out" of the minimal FL requirement for graduation from UNCA: two semesters of beginning FL study. As far as experiences with "other cultures," these will typically have been with the relatively small Native American or African-American populations in the region, or with the small but growing Hispanic (and Spanish-speaking) population. Other cultural groups (Eastern European, Asian, Indian, Middle-Eastern) are present but in extremely small numbers.

${ }^{4}$ Such fusions constitute an observable trend in North American universities at present. As both public and private resources have shifted to more directly career-oriented subjects of undergraduate study, such as Computer Science, the traditional humanistic subjects, such as Philosophy, History and the various languages have entered a period of scarcity. In the case of the foreign languages, this has meant the collapse of separate departments (German Language and Literature, French Language and Literature, Spanish Language and Literature, etc.) into single departments ("Languages and Literatures"). While this is certainly preferable to the elimination of language study altogether from higher education, the logical endpoint of such evolution - a single "Department of Humanities" - is undesirable for a great many reasons, not least of which is the forfeiture of faculty diversity and expertise.

${ }^{5}$ Quoted from an intra-departmental document mandating the Shared Experiences.
} 
environment". It was decided that the Shared Experiences workshops were to occur three times over the course of a single semester, and were to involve all students enrolled in intermediate $\mathrm{FL}$ courses $^{6}$ - or as many as possible, given the perennial logistical challenges presented by classroom availability and scheduling.

\section{Theoretical basis of the project}

As the faculty who eventually emerged as co-directors of this pilot program, Dr. Lorrie Jayne and I were granted broad leeway in terms of design, implementation and overall approach. In effect, we could shape the program as we saw fit. Our perception of the institutional context, however, combined with the nature of the departmental mandate and our own individual scholarly interests and areas of expertise, led us to choose Intercultural Communicative Competence (ICC) as the primary focus of the project. While some elements of ICC could be seen as natural byproducts of FL study, the Shared Experiences mandate seemed to us to present a unique opportunity for addressing this complex of attitudes, knowledges and skills more directly. The fact that the workshop participants would be drawn from the different departmental "languaculture" concentrations seemed fortuitous in this regard, since it opened a space for exploring more deeply the notion of culture itself using the lingua franca of English.

Granted, English is by no means a neutral medium. Nor is it monolithic; and this was seen as an essential part of the Shared Experiences, for it meant that there was no position "outside" the intercultural dynamic, and hence no basis for any claims of objectivity. Thus although conducting the sessions in English was in one sense a practical necessity (it was the only language we all had in common), it also had the theoretical value of necessarily involving the participants in a process of self-awareness and critical reflexion. Here the notion of languaculture, mentioned above, revealed both its theoretical power and its utility.

The notion stems from the American anthropologist Michael Agar ${ }^{7}$ (1995), and is intended to emphasize the inextricability of language and culture, particularly in the context of languagelearning. Of particular importance for our work here is the way the concept of languaculture allows for (indeed, necessitates) an interrogation of ideas of language and culture that are formulated in national or monolithic terms, terms which - certainly in the case of German, French, Spanish and English - are rooted in the history of colonialism. Unfortunately, though

\footnotetext{
${ }^{6}$ Called "200-Level Courses" at UNCA, these are credit-bearing courses generally designed for students majoring or minoring in a FL or who have "tested out" of the basic FL requirement but who want more language coursework ("heritage speakers," for example).

${ }^{7}$ For a more recent elaboration, see Risager (2006).
} 
not surprisingly, the U.S.-American university system - UNCA included - still adheres to a system of academic disciplines that tends to reinforce this form of essentialism. Consequently, curricula like the Shared Experiences are perhaps all the more important as a form of critical inquiry and resistance. By speaking of languacultures and by revealing their diversity, complexity and mutual imbrication, our hope was to dismantle the essentialism inherent, for example, in the phrase "Spanish culture," and to open the way for a more nuanced, critical, and reflexive intellectual experience. Indeed, the ultimate aim was to encourage students to understand "identity" (their own and others') as complex, constructed, and negotiable. Thus although the immediate focus of the sessions was to be Intercultural Communicative Competence, we viewed this within a field of larger concerns, including decolonization and anti-racism.

It is no secret that the notion of ICC, like the notion of culture itself, continues to enjoy a remarkable conceptual diversity - if not to say confusion. Not only do business people, professional workshop leaders, culture consultants, sociologists, anthropologists, linguists and language teachers have different vocabulary for these ideas, but even when they speak the same conceptual language of intercultural communication, intercultural competence or interculturality, they mean apparently different things by these terms. It would exceed the scope of this paper to attempt to sort all of this out. But a degree of conceptual clarity seemed absolutely necessary for the purpose at hand, since that purpose involved not only teaching and learning and but also the goal of meaningful assessment. For our purposes, then, and drawing in large part upon the work of Michael Byram (1997), we defined ICC as a complex of 1) attitudes and awareness, 2) knowledges and 3) skills necessary to perform appropriately and effectively when interacting with others of a different languacultural background.

Among the important attitudes are:

1. a basic alertness to/awareness of/curiosity about cultural differences

2. an acknowledgement of the identities of others as fundamentally valid

3. a capacity to imagine and empathize with others' experiences and points of view

4. a fundamental respect for others and a willingness to enter into the dynamic, reciprocal relationship of dialogue

Among the important knowledges are:

1. an understanding of the complexity of languaculture per se (see "The Iceberg Model of Culture") 
2. specific dialectical knowledge ${ }^{8}$ of the languaculture of the other

3. specific dialectical knowledge of one's own languaculture

4. specific knowledge of potential "friction zones" between the two

Among the important skills are:

1. ability to suspend judgement while listening, observing, interacting with the other

2. ability to perform appropriately and effectively in communicative situations

3. ability to intervene in communicative situations in order to elucidate/alleviate "friction"

4. ability to collaborate with languacultural others on projects of mutual interest and benefit $^{9}$

These twelve items were thus in effect the learning outcomes for the project. (See below for how these projected outcomes were integrated with assessment.)

Furthermore, we determined to take the rubric Shared Experiences literally, i.e. to make the workshops experiential and interactive, rather than merely discursive. This determination was made not merely for practical reasons (the large number of participants would make readings and discussion difficult to manage) but also because the dimensions of culture we wished our students to explore belong to the field of "subliminal" values ${ }^{10}$ - such things as conceptions

\footnotetext{
${ }^{8}$ By dialectical knowledge we meant knowledge that arises within the dynamic and reciprocal process of an intercultural encounter. By way of example, take the commonplace that "Germans are obsessed with rules." This is of course a stereotype, which may or may not be useful in an encounter with an actual German. But more importantly, it only makes sense from a certain point of view. If I come from a culture in which spontaneity is valued, then it is perhaps understandable that I would perceive German culture this way. And yet it is possible to imagine a cultural point of view (and perhaps one exists) from which the Germans would appear unconscionably slack in terms of rules. Hence intercultural knowledge is always "dialectical": it emerges in a particular dialogic context, and it is dynamic and evolving. (In the above example, my deepening experience of German culture might eventually lead me to conclude that Germans are not so much rule-obsessed as they are interested in certain values such as order, transparency, predictability and reliability. And even this dialectical "move" will be transcended as I continue to have experiences with different individuals from other parts of the German-speaking world.) Of crucial importance here is the idea that this process is reciprocal: I cannot learn about the culture of the person across from me without at the same time learning about my own culture, since my own culture is the "lens" through which I experience the other culture. And yet, by becoming aware of the "lens" itself, I am also at the same time "dialectically" sublating that position and taking up a third position outside the dialogue. Thus, according to Arnd Witte and Theo Harden, "this third space is the locus of intercultural competence." (Witte \& Harden, 2011, p. 5).

${ }^{9}$ This last skill is taken up by Michael Byram as an essential component of what he calls intercultural citizenship: "Intercultural citizenship goes beyond [intercultural competence], involving both activity with other people in the world and the competences required for dialogue with people of other languacultures." (Byram, 2012, p. 92).

${ }^{10}$ We're drawing here on the widely-used "iceberg model of culture." Although frequently attributed to Edward T. Hall (1976), the image does not in fact appear there. Instead, it seems to have been first applied to Hall's surface/depth model of culture by Gary Weaver, who, for his part, is quite explicit about borrowing the image of the iceberg from Sigmund Freud. Freud, however, used it to describe not culture per se but the individual human psyche (Weaver, 1986).
} 
of space and time, notions of honor, friendship, respect, the significance of the body and of physical touch, eye contact, silence, etc. - values, in short, that are not so much espoused by as embodied in the members of a given cultural community. Since these embodied values are what we see performed when members of a cultural group (or of different cultural groups) interact, it stands to reason that they can be best discovered, engaged, and learned performatively, that is to say, holistically through the body and senses, the emotions, the imagination and the moral intelligence as well as the rational intellect. ${ }^{11}$ In short, it was decided that our approach would be primarily performative rather than informative.

By calling this an approach rather than a method, our intention was to emphasize - and to remind ourselves of - the fundamental flexibility of going performative in terms of the parameters of particularity, practicality and possibility. As Dragan Miladinović has recently pointed out, these parameters mark performative teaching and learning as "post-method":

PFLT [performative foreign language teaching] does not claim to be the 'only correct' method. Here it is important to emphasize that PFLT [...] must be treated as open and adaptable. That is to say, PFLT can be modified to suit new target groups, because it places leaner and their individuality in the center. PFLT initiates processes of personal reflexion in the learner that can be developed further, and it does so particularly through aesthetically and somatically oriented experiences. In the sense of post-method, the teacher is empowered to investigate their own teaching, to reflect upon their own role therein and to act in accordance with their conclusions. (Miladinović, 2019, p. 17, translated by JC). ${ }^{12}$

As Miladinović goes on to argue, the performative approach is an approach based on principles rather than on prescribed practices. The principles, in fact, are what enable one to select the practices that are most appropriate for a given context. This fundamental flexibility - in terms of adapting to specific context, emphasizing individual reflexive learning processes catalyzed by aesthetic/embodied experiences and supporting the teacher-as-researcher - make the performative "post-method" particularly well suited to doing intercultural work.

\section{Design of the project}

As far as their actual content, the three Shared Experiences workshops were mapped onto the three-part structure of intercultural competence described above: Attitudes/Awareness,

\footnotetext{
${ }^{11}$ For a fuller overview of performative pedagogy in FL teaching, see Schewe (2013).

${ }^{12}$ Miladinović is drawing here on the work of Balasubramanian Kumaravadivelu. See Kumaravadivelu (2006) for a fuller treatment of the three parameters of postmethod teaching.
} 
Knowledges and Skills. Because this structure is also to a certain degree diachronic, i.e. developmental, the three workshops were planned as a sequence, in which each instance would build upon the one previous. ${ }^{13}$

Moreover, since this was a pilot program, we considered it essential to accompany the Shared Experiences with some form of empirical assessment that would give us feedback on the strengths and weaknesses of our efforts, and hence guide us in re-shaping the program for fuller implementation in future semesters. Given the emphasis on experiential learning, this meant obtaining qualitative data on the participants' actual experiences in the workshops. It seemed to us that anonymous short-answer questionnaires would be the simplest way to achieve this. ${ }^{14}$ We therefore designed a sequence of three simple questionnaires tailored to the three Shared Experiences which the participants would fill out two days after each workshop. ${ }^{15}$ The overall plan thus had the following pattern (Fig. 1):

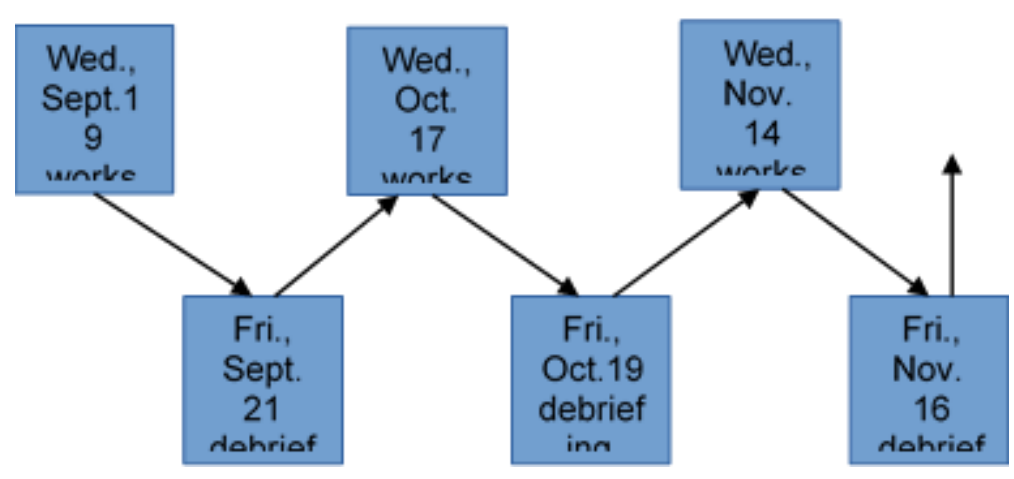

Figure 1: Schedule of workshops and debriefings

This design had the advantage of 1) giving students time to absorb and reflect upon their experiences before attempting to articulate them in writing and discussion, and 2) affording us, as program leaders, the opportunity to adjust our approach as we went along, based upon the feedback we were getting each time. It also enabled us to look for patterns both "vertically" (within a given workshop) and "horizontally" across all three workshops. Hence we could draw some provisional conclusions about how well specific techniques, materials

\footnotetext{
${ }^{13}$ This tripartite structure has numerous sources and permutations. For our model, we also drew on Hofstede (2002).

${ }^{14}$ Alvino Fantini has pointed out the "myriad assessment instruments" available for measuring the development of intercultural communicative competence, often involving (or tacitly presupposing) different concepts of ICC. The simple approach adopted here was considered the most appropriate both to our concept, to the formal structure of the workshops themselves, to the heuristic nature of a pilot program per se, and to the institutional context (Fantini, 2012, p.391).

15 The participating language classes met three times per week, Mondays, Wednesdays and Fridays for 90 minutes each time. Because each of our Shared Experiences took up an entire Wednesday class period, we felt it was necessary to devote the following Friday class period to our "debriefing": the administration of the questionnaire, followed by a group discussion.
} 
and activities had worked in a given "Shared Experience" as well as track participants' learning over the course of the entire program. This, again, seemed important as a way of grasping the processual dimension of intercultural learning described above. ${ }^{16}$

Unfortunately, due to a scheduling conflict, only students in 200-level French and German were able to participate consistently in the pilot program, hence only their questionnaires were used as data for the present study. (Students in 200-level Spanish joined the program in the Spring semester of 2019, after the period covered in this first phase of the study.) In total there were 18 student participants: 12 German students and 6 French students. Other visitors (including international students, see below) participated from time to time, but were not part of the data for the study.

The following sections describe the curricular content of each of the three Shared Experiences as well as the data obtained via the anonymous questionnaires.

\section{Shared Experience \#1: Attitudes and awareness}

The first "Shared Experience" occurred on Wednesday, September 19, 2018. The purpose of this session was twofold: to introduce and justify the Shared Experiences curriculum itself, and to begin the process of intercultural learning by raising participants' awareness of and curiosity about cultural differences. To some extent, these two purposes overlapped. For the first part of the session, we invited a guest to join us who happened to be a visiting writer on campus at that time: the Mayan poet and teacher Donny Brito May (see Figure 2). In his presentation, which lasted about 20 minutes and was given entirely in Spanish (with one of our faculty serving as interpreter), Señor May described one of the fundamental aspects of teaching in his native Mayan languaculture: the use of "manipulatives" by teachers and students alike. Señor May demonstrated this during his presentation by manipulating a variety of small objects - mostly traditional toys and simple musical instruments - while speaking. ${ }^{17}$

\footnotetext{
16 It should be noted that each participant was given a unique number for the purpose of filling out the questionnaires, so that while the respondent's personal identity was concealed from us, we were still able to track how an individual participant fared across all three workshops.

${ }^{17}$ Readers will note that this use of "manipulatives" is rather different from their typical use in the classroom, where they are closely (and often mimetically) related to a particular lesson and a particular teaching objective. As the now famous "Nobject Study" of Kiefer et al. (2007) has demonstrated, however, such mimetic relations to learning are entirely unnecessary, and even where the manipulated object and its associated gestures have nothing at all to do with the "concept" or "content" of the lesson, alone the physical act of manipulation enhances learning.
} 


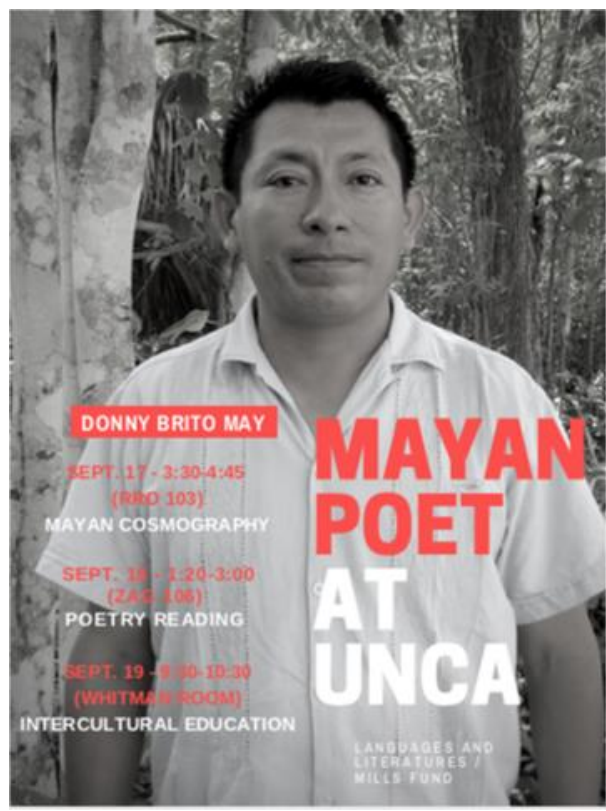

Figure 2: Promotional flyer for Donny Brito May

For most of the workshop participants, it was strange indeed to see a university teacher "fiddling" with something while teaching; but as Señor May explained, this activity was rooted in the original context of teaching in his culture. Among the Maya, teaching is integrated into daily life, occurring, for example, while both teacher and student are engaged in a mundane activity such as preparing food. The body is thus "engaged" and active, although in a way that may or may not bear any obvious semiotic relation to the subject of teaching. ${ }^{18}$

Señor May's demonstration was followed by a discussion in plenum in which workshop participants were given the opportunity to handle the manipulatives themselves while asking questions of Señor May. The manipulatives remained available for the participants' use throughout the session.

The second part of the workshop featured three short scenic performances by UNCA faculty members based upon their own personal experiences with culture shock (Figure 3). ${ }^{19}$ These

\footnotetext{
${ }^{18}$ Nothing could be further, of course, from the traditional mode of teaching in most of the industrial world, where learners go to a special place (a school) in which they are expected to sit still for long periods of time. To play or "fidget" with a small toy while in class would be considered a disruption and would likely be punished accordingly - unless explicitly allowed under a particular student's "academic accommodations."

${ }_{19}$ Although based upon actual experiences with the three main languacultural zones represented in the Department (German, French and Spanish), these skits were presented in a "pure" form, i.e. without language or other identifiable cultural markers. This was done in an attempt to insulate the activity from the cultural stereotyping that might otherwise have clouded the students' perceptions. (If they knew a skit was set in France, for example, they might tend to perceive and interpret its drama in a certain stereotypical way.) At this point in the Shared Experiences the emphasis was not on the identification and deconstruction of specific cultural stereotypes, but on the perception of "intercultural moments," i.e. interactions in which cultural difference plays a decisive role. In particular, the three skits we presented dramatized cultural differences of personal space (proxemics), smiling, and relations between the genders.
} 
performances were followed by a brief discussion in plenum, in which the students were asked about what they had noticed in the performances, and what, in their view, had "gone wrong" in the interactions represented.

What emerged from this discussion was two-fold: 1) a rudimentary perception of the difference between explicit and implicit aspects of culture, and 2) the beginnings of a selfreflexive or intercultural process. One scene, for example, showed a group of people standing in line. A woman in the middle of the line becomes increasingly and visibly irritated at the physical proximity of the man behind her. She undertakes various actions designed to open more space between herself and him, but the man (who is reading a newspaper) intuitively re-closes the gap each time. This happens again and again, until eventually the woman gives up and goes to the back of the line. There the drama repeats itself - this time with another woman who arrives after her. When asked what they had observed, one student said, "They're standing way too close." Another said, "They're invading her personal space." To these and similar observations, the workshop leaders pointed out that the students seemed to be identifying with the uncomfortable woman as "protagonist" of the drama, and to be tacitly validating her point of view as "correct." The reason for this, as the ensuing discussion made clear, was that the woman's "sense of personal space" corresponded, in terms of its basic dimensions and dynamism, to the students' own. No one, it was pointed out, felt that the woman was being strange, over-sensitive, anti-social or paranoid, even though to the other people standing in line she may very well have appeared that way. If we imagine her as a guest or visitor in a foreign country, then the statement "They're too close" would actually have to be inverted: "She's too far away." Her behavior, in other words, shows little flexibility or tolerance for the culture she's visiting, at least in terms of personal proxemics.

In this way, the discussion naturally led to the self-reflective moment, which is also the moment of entering the "third space" of interculturality: the students began to see how it was in fact their own cultural point of view that to a great extent determined what they were seeing in the cultural other. They also began to see how neither position in this dialectic was inherently "correct."

As these perceptions began to accumulate, the workshop leaders introduced the notion of the "Iceberg Model of Culture" using a large poster-board graphic. This served not only as a convenient visual metaphor for a new concept of culture, it also helped organize the discussion. It became possible to think concretely about aspects of culture that lie "below the surface" of language, dress, cuisine and customs, etc., particularly those aspects that usually remain unconscious, but which are embodied and performed in everyday life. 


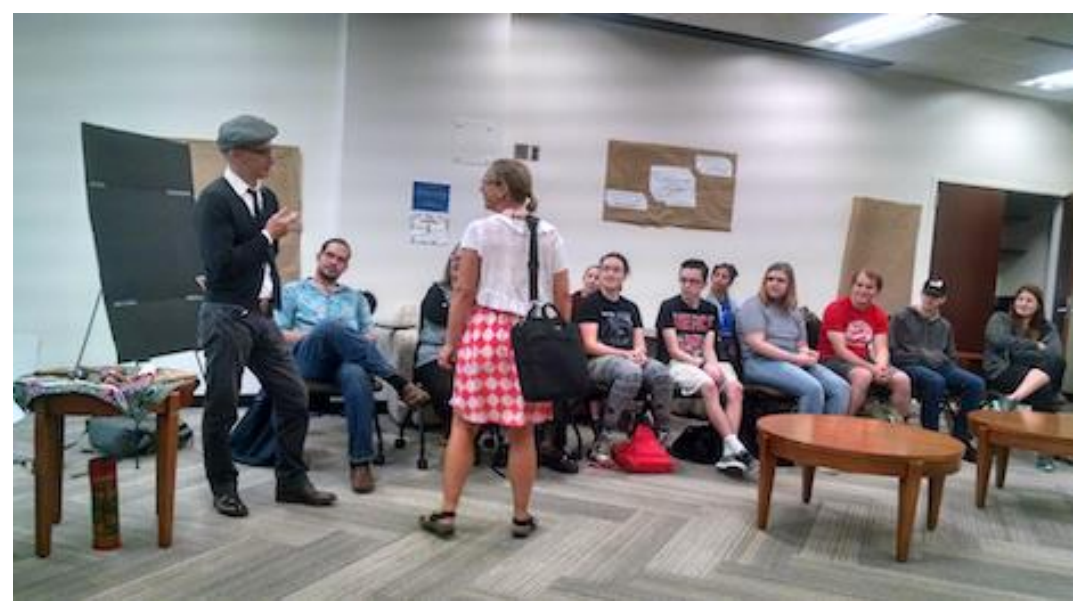

Figure 3: Faculty performing culture shock skit

At this point, the group was divided into sub-groups of four-to-five, in which students were "mixed and matched" from the French and the German classes, along with faculty and visitors. Their task as a group was to share personal experiences which they felt exemplified the kind of intercultural "friction" they had witnessed in the skits and begun to understand in terms of the "iceberg" model. Additionally, each group was given a manipulative to work with during their discussion, the idea being that it would function as a "talking stick," i.e. whoever wished to speak would take up the manipulative and return it to the middle of circle when they were done (see Figure 4).

These small-group discussions were then followed with a final return to the plenum format, in which each group reported on its discussion. In this phase, the faculty leaders sought to elucidate those moments in which the "implicit" dimension of culture was thematized, and in which the dialogic nature of intercultural encounter, and hence of intercultural learning itself, became clear. Specific elements were referred to the visual of the iceberg. The discussion eventually had to be broken off as the time allotted for the workshop had run out.

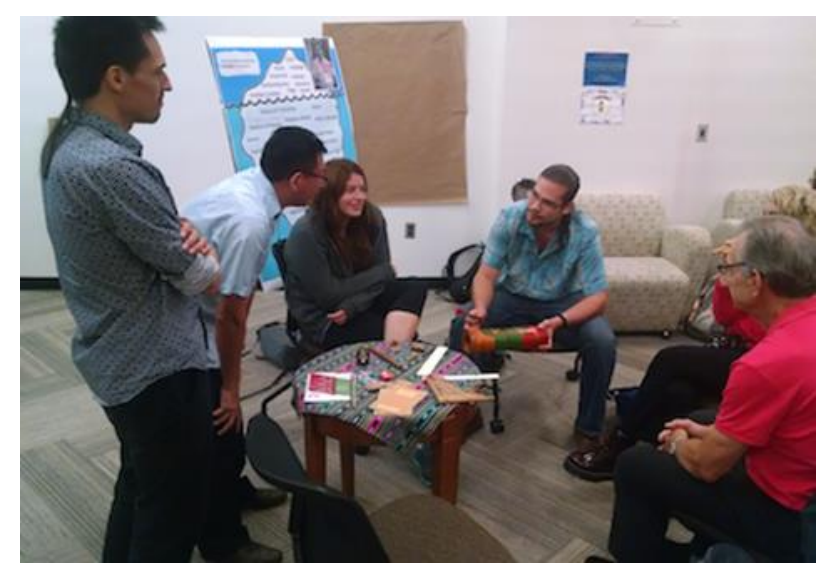

Figure 4: Small group discussion using manipulatives

During the communal debriefing the following Friday, an anonymous questionnaire was distributed with the following questions: 
1. What three things did you learn from the first Shared Experience?

2. What do you want to learn more about?

3. What do you consider to be the best part of the Shared Experience and why?

4. What would you like to see in future Shared Experiences?

These handwritten questionnaires were then collected before a general discussion began. The discussions, in which the students were asked to articulate and respond to each other's experiences, provided the project leaders with a rough sense of the overall strengths and weaknesses of the first Shared Experience before evaluating the data in the questionnaires. This was important, because it provided an additional (if informal) point of triangulation.

The responses to the questionnaires were transcribed and evaluated for prominent themes and recurring motifs. The table below indicates the themes/motifs for each set of answers, and ranks them according to frequency, along with a representative quote.

\begin{tabular}{|c|c|c|}
\hline Question & Major themes & Representative quotes \\
\hline $\begin{array}{l}\text { 1. What three things did you learn from } \\
\text { the first "Shared Experience"? }\end{array}$ & $\begin{array}{l}\text { a. aesthetic relation to } \\
\text { language } \\
\text { b. language and culture } \\
\text { c. skepticism }\end{array}$ & $\begin{array}{l}\text { "Language is beautiful and exciting again." } \\
\text { "I learned that learning can be very fun." } \\
\text { "Culture and language are more closely connected } \\
\text { than I thought." } \\
\text { "Interacting with the material culture helps with } \\
\text { learning the language." } \\
\text { "I don't really feel like I learned all that much." }\end{array}$ \\
\hline $\begin{array}{l}\text { 2. What do you want to learn more } \\
\text { about? }\end{array}$ & $\begin{array}{l}\text { a. intercultural strategies } \\
\text { b. cultural specificity } \\
\text { c. rationale }\end{array}$ & $\begin{array}{l}\text { "How to deal with cultural differences in } \\
\text { interactions with people from other cultures." } \\
\text { "I would like to learn more about everyday } \\
\text { experiences living in another country." } \\
\text { "I want to continue learning more about the } \\
\text { specifics of other cultures through stories, } \\
\text { literature, music and really any way that can } \\
\text { broaden my knowledge of other cultures." } \\
\text { "I would like to know more about the ultimate } \\
\text { purpose and objectives of these meetings." }\end{array}$ \\
\hline $\begin{array}{l}\text { 3. What do you consider to be the best } \\
\text { part of the "Shared Experience," and } \\
\text { why? }\end{array}$ & $\begin{array}{l}\text { a. community } \\
\text { b. alternative pedagogy }\end{array}$ & $\begin{array}{l}\text { "The best part was probably when we split into } \\
\text { groups and were able to talk to different language } \\
\text { students or get to know our classmates better." } \\
\text { "The best part ... was getting to break into groups } \\
\text { and talk while interacting with the objects the } \\
\text { guest speaker brought." } \\
\text { "The Mayan poet and his teaching methods. It } \\
\text { was the best part for me because I knew very little } \\
\text { about Mayan culture." } \\
\text { "Watching professors do skits because they were }\end{array}$ \\
\hline
\end{tabular}




\begin{tabular}{|l|l|l|}
\hline & & $\begin{array}{l}\text { able to express their first-hand experiences to the } \\
\text { audience. Also it was funny." }\end{array}$ \\
\hline $\begin{array}{l}\text { 4. What would you like to see in future } \\
\text { Shared Experiences? }\end{array}$ & a. cultural specificity & $\begin{array}{l}\text { "Talk about specific features of language/cultures } \\
\text { in the department (German/French, etc.)." } \\
\text { "I'd like to see lots of different ways other cultures } \\
\text { can be learned about. Maybe through food?" } \\
\text { "I'd like to see a greater focus to the overall } \\
\text { session, with clear objectives and purpose in } \\
\text { mind." }\end{array}$ \\
d. skepticism & $\begin{array}{l}\text { "No opinion, I feel like it takes away from valuable } \\
\text { class time that I would prefer to use for learning } \\
\text { the language I'm interested in. We all seem to } \\
\text { have similar experiences and I don't think we gain } \\
\text { much from sharing them." }\end{array}$ \\
\hline
\end{tabular}

Table 1: Session 1 participant feedback

After evaluating the student feedback (questionnaires plus debriefing), we determined that the majority of students had indeed achieved a basic awareness of the "implicit" dimension of culture. Furthermore, we determined that the essentially experiential/performative approach had been both interesting and effective, although its effectiveness in terms fo learning was closely associated with the time allocated for substantive discussion, particularly in small groups.

In these limited regards, then, our first session was successful. Even the frequently expressed desire for greater specificity relating to French and German cultures was taken as confirmation of our original plan, since it pointed toward one of the tasks we had set for the second "Shared Experience," namely, to focus on concrete knowledge of cultural differences (i.e. the dialectic of self and other). But the feedback also made us aware of certain challenges moving ahead, particularly with respect to framing and justifying our work theoretically in a way the students would find compelling. We therefore deduced a list of pedagogical "take-aways," i.e. lessons for implementation in the following session. These were as follows:

1. Aim for better organization and focus.

2. Emphasize hands-on, interactive or performative experiences (haptic, auditory, kinaesthetic, etc.) rather than textual/discursive modes of presentation.

3. Emphasize cultural specificity.

4. Emphasize small-group work (give students more opportunities to work together).

5. Invite international guests to participate whenever possible. 
This first round of feedback also had the value of alerting us to certain perhaps more intractable challenges, the most important being how to justify the project to skeptical students and to persuade them of its value. ${ }^{20}$

\section{Shared Experience \#2: Knowledge}

Our overarching purpose in this second session was to deepen participants' awareness and knowledge of their own culture(s) with respect to the particular dimensions of eye contact, physical contact and silence. Moreover, in an attempt to integrate as many as possible of the take-aways from the first Shared Experience we structured the second Shared Experience according to the basic principles of drama pedagogy ${ }^{21}$. Thus we began by preparing the space together (i.e., clearing away unnecessary furniture and personal items) and then did a simple group-warm-up ${ }^{22}$. This was immediately followed by a more extensive group improvisation exercise called "Brief Encounters," in which participants were guided through an experimentation with sustained eye-contact, sustained physical contact, and (literally) "blind" trust - without the support of language ${ }^{23}$. The session closed with a cool-down period of reflection in the form of, first, small-group discussions using manipulatives and, second, a guided discussion in plenum. As part of this group discussion, we began to lay out the basic theoretical framework of intercultural learning and Intercultural Communicative Competence. Our purpose here was not only to provide a rational framework to help students articulate and understand their experiences in the exercise and elsewhere, but also to offer an overarching "justification" for the Shared Experiences curriculum. As part of this more theoretical component, we asked the students to consider the following quote from Alvino Fantini:

The task as foreign language learners, then, is to recognize and clarify one's own view, or perspective, while attempting to learn about the

\footnotetext{
${ }^{20}$ It should be noted here that the most pointed expressions of skepticism came from a single student. As will be seen below, this student's stance toward the project persisted to the end. While it would be tempting to dismiss this as an isolated instance, or as symptomatic of a certain personal inflexibility or lack of intellectual curiosity, the student's objections are not, in and of themselves, irrational or absurd. On the contrary, they point to one of the key challenges facing any attempt to integrate performative intercultural work into the conventional foreign language curriculum.

${ }^{21}$ This entails a basic three-part structure of warm-up, deepening, and cool-down. An in-depth analysis of this structure as it relates to performative foreign language pedagogy can be found e.g. in Sambanis (2013, see esp. Chapter 5, "Dramapädagogik")

${ }^{22}$ We used the simple game "Zip-Zap-Zop-Boing" familiar from theater and improv classes. This has the multiple advantages of sharpening participants' sensory awareness of each other, activating their responsive nervous system, and warming up the physical body in a posture of neutral readiness or "poise".

${ }^{23}$ The purpose was to raise the participants' awareness of their own comfort zone with these forms of interaction. See Crutchfield (2018) for a detailed description of the exercise and a reflection upon its usefulness and limitations.
} 
views of others. In the end, although we may not necessarily develop native-like proficiency, we may aspire to some degree of ability to communicate, behave, and interact in the style of the target culture members. (Fantini, 2009, 197)

The emphasis here lay on the notion of dialectical knowledge ("recogniz[ing] and clarify[ing] one's own view, while..." etc.) and on the concept of languacultural style. It turned out that style in this sense provided the students with a useful shorthand for their new understanding of culture-as-performance: just as one can learn to dance in a particular style, one can also learn to perform in a particular languacultural style, without thereby giving up one's own style. Style is after all a flexible concept, both synchronically and over time. While one can speak of general rules or tendencies that characterize a given style, these are by no means rigid and prescriptive, but instead allow for significant personal, familial, communal, and regional variation. And of course: they evolve. This insight, e.g. that "French culture" is neither monolithic nor eternal, and that one need not "become French" in order to perform effectively and appropriately - and perhaps even with real artistic élan - in a French languacultural style, this insight proved both a comfort and an encouragement to the students, and was a decidedly positive note on which to end the workshop.

The questionnaire distributed during the subsequent debriefing session contained the following four questions:

1. In your own words, explain ICC. Why is it important?

2. What, for you, was the most valuable part of the second Shared Experience?

3. How could you apply what you've gleaned thus far from the Shared Experiences to your own foreign language learning process?

4. We have one more Shared Experience planned. What would you most like to explore in relation to ICC?

The data from the subsequent questionnaires and debriefing session were as follows (see Table 2):

\begin{tabular}{|c|c|c|}
\hline Question & Major themes & Representative quotes \\
\hline $\begin{array}{l}\text { 1. In your own words, explain ICC. Why } \\
\text { is it important? }\end{array}$ & $\begin{array}{l}\text { a. respect } \\
\text { b. avoiding conflict }\end{array}$ & $\begin{array}{l}\text { "[ICC] is the ability to grasp, appreciate and } \\
\text { respect different cultures beyond understanding } \\
\text { of the language." } \\
\text { "ICC is the ability to adapt to situations in which } \\
\text { two or more cultures are coming together by } \\
\text { identifying the differences in communication and } \\
\text { change [sic] the way you act/perceive to avoid } \\
\text { miscommunications." }\end{array}$ \\
\hline
\end{tabular}




\begin{tabular}{|c|c|c|}
\hline & $\begin{array}{l}\text { c. reciprocity/reflexion } \\
\text { d. embodiment }\end{array}$ & $\begin{array}{l}\text { "ICC is understanding how you perceive others } \\
\text { from another nation or culture and maybe more } \\
\text { importantly how you are perceived by them." } \\
\text { "ICC is understanding your own culture, the } \\
\text { culture of the area/language you're studying and } \\
\text { how the two intermingle." } \\
\text { "Being able to understand body language and } \\
\text { ways of speaking in your own culture and being } \\
\text { able to interpret and use the different ways of } \\
\text { expression in other cultures." } \\
\text { "Being able to not only speak a language but } \\
\text { perform it." }\end{array}$ \\
\hline $\begin{array}{l}\text { 2. What, for you, was the most } \\
\text { valuable part of the second "Shared } \\
\text { Experience"? }\end{array}$ & $\begin{array}{l}\text { a. eye contact and trust } \\
\text { b. discussion/reflection } \\
\text { c. negative emotions }\end{array}$ & $\begin{array}{l}\text { "The exercise of trusting another, looking in the } \\
\text { eyes was for me a very interesting experience." } \\
\text { "Making direct eye contact. It made me realize } \\
\text { that eye contact is often deemed uncomfortable." } \\
\text { "Being led around the room with my eyes closed } \\
\text { because my brother's girlfriend is blind and it gave } \\
\text { me a little bit more perspective into what her life } \\
\text { is like." } \\
\text { "The discussion following the closed eye leading } \\
\text { exercise. This helped show the value of the } \\
\text { exercise in a way which was not immediately } \\
\text { apparent." } \\
\text { "The reflection is the most important part, } \\
\text { because we all get to express what we thought } \\
\text { about it." } \\
\text { "To be completely honest I do not value these } \\
\text { sessions very much, in fact they mostly just stress } \\
\text { me out. Why? Because I have social anxiety and } \\
\text { don't like being forced to interact with others." }\end{array}$ \\
\hline $\begin{array}{l}\text { 3. How could you apply what you've } \\
\text { gleaned thus far from the Shared } \\
\text { Experiences to your own foreign } \\
\text { language learning process? }\end{array}$ & $\begin{array}{l}\text { a. awareness/ observation } \\
\text { b. open-mindedness } \\
\text { c. personal growth }\end{array}$ & $\begin{array}{l}\text { "I will be more conscious about how I behave } \\
\text { when I get to the different countries." } \\
\text { "Paying attention to differences that I notice } \\
\text { when talking to people with different } \\
\text { backgrounds." } \\
\text { "Observation and mimicking can fill the gaps left } \\
\text { by vocabulary." } \\
\text { "Don't be too quick to take offense when in } \\
\text { another culture because it was probably } \\
\text { unintentional." } \\
\text { "Helping to stay open-minded when visiting a new } \\
\text { place and exiting my comfort zone in order to } \\
\text { better integrate myself in their culture and grow } \\
\text { as a person." } \\
\text { "Using this understanding of cultural differences } \\
\text { to help me grow as a person." }\end{array}$ \\
\hline
\end{tabular}




\begin{tabular}{|c|c|c|}
\hline & d. skills/application & $\begin{array}{l}\text { "It would better help my communications skills } \\
\text { with people from other cultures." }\end{array}$ \\
\hline $\begin{array}{l}\text { 4. We have one more "Shared } \\
\text { Experience" planned. What would you } \\
\text { most like to explore in relation to ICC? }\end{array}$ & $\begin{array}{l}\text { a. strategies } \\
\text { b. cultural specificity } \\
\text { c. food }\end{array}$ & $\begin{array}{l}\text { "We have talked a lot about how to identify } \\
\text { cultural differences but haven't talked much } \\
\text { about how to handle them. Talking more about } \\
\text { 'coping mechanisms' would be helpful." } \\
\text { "Can we discuss application of ICC in } \\
\text { communication more?" } \\
\text { "I would love more examples of specifically what } \\
\text { to expect/how to carry myself." } \\
\text { "I would like to learn more about the differences } \\
\text { between German and French culture." } \\
\text { "The food of different cultures, food is extremely } \\
\text { important in most cultures and one can learn a lot } \\
\text { from food of a culture." }\end{array}$ \\
\hline
\end{tabular}

Table 2: Session 2 participant feedback

Our evaluation of the data on this session led us to the following conclusions:

1. The extended experiential exercise ("Brief Encounters") was the most successful element of the session, but the discussions afterward were essential to that success.

2. The students had achieved a deeper knowledge of their own culture(s) in terms of "implicit" values, and were able to imagine how these might inform their interactions with people from other cultures.

3. Only some students were able to make the connection between interculturality and larger humanistic values of respect, compassion, the suspension of judgement, etc.

4. Most of the students were still eager for greater practical knowledge of the cultures they were studying (German and French), as well as for practical skills for negotiating specific cultural differences.

5. The experiential/performative approach, by requiring unusual forms of personal interaction between students, carried with it the danger of pushing certain students too far out of their comfort zone, leading to negative emotions and hence a decrease in learning. 
This last point deserves elaboration. While it is certainly true that performative work, by virtue of being holistic, necessarily involves the risk of negative or unpleasant emotions ${ }^{24}$, it is also true that there are significant differences among individual learners in terms of precisely where the threshold of discomfort lies. For some students, the threshold lies already at the classroom door. Here we are speaking of a population of students with (in some cases undiagnosed) social anxieties or other psycho-pathologies that may make, for example, the simple act of touching another person or looking another person in the eyes for any length of time quite impossible. ${ }^{25}$ Obviously, it won't do to coerce such students to participate, least of all in the all-too-easily patronizing interest of "helping them overcome their fear." And yet, surely that is also part of what a teacher is called upon to do?

There is alas no clear solution to this conundrum. In the end, our decision was to allow anyone whose discomfort rose beyond what they considered a tolerable level to "exit" the exercise at any point, or to take up the position of "observer" from the start. Of crucial importance in these cases, however, was to make sure such students still felt "included" and valued. In general, this could be achieved by explicitly tasking them with the job of observing the group during the exercise - in the manner of "cultural anthropologists" - and asking them to relate their observations to the group in the subsequent discussion. In many respects, this etic point of view became a valuable complement to the emic point of view of the participants themselves. Quite often, the "anthropologists" noticed patterns of behavior that escaped the attention of the individual participants. Having the "anthropologists" (instead of the workshop leader) relate these observations brought the added advantage of keeping the students at the center of the learning process, making their own discoveries and articulating their new knowledge in their own words.

\section{Shared Experience \#3: Skills}

For the third and final Shared Experience, our intention, shaped both by the student feedback on the first two and by our overarching three-part plan, was to focus on specific features of the target languacultures (French and German) and on specific skills that might help our students negotiate them in real life. At this point, since the dimensions of culture we had been endeavoring to bring to light were to a large degree "embodied" and subliminal, it seemed to

\footnotetext{
24 The artistry on the teacher's part being the ability to both "validate" and "contextualize" these emotions in such a way as to harness their energy for the benefit of the learning process itself (see Crutchfield, 2015).

${ }^{25}$ This is, I would argue, qualitatively different from the discomfort that might arise for cultural reasons. (For example, the Japanese student for whom eye contact with a social superior would be avoided out of a sense of respect.) This "cultural" discomfort is, after all, exactly what the performative work is designed to bring to the surface experientially and hence to make available for analysis.
} 
us essential that actual members of the target languacultures be invited to join our group for face-to-face interaction. ${ }^{26}$ This would not only provide our students with the (for them, rare) opportunity for authentic encounters with individual Germans and French, but would also foster a deeper sense of dialogue and community on campus around the issue of interculturality. ${ }^{27}$ Fortunately, there were at that time three exchange students at UNCA who were interested in joining us, one from Germany, one from Austria, and one from France. (As will be seen from the data below, the students overwhelmingly considered this the most valuable aspect, not only of the $3^{\text {rd }}$ Shared Experience, but of the entire Shared Experiences curriculum.)

We began the session once again with a simple group warm-up, this one adapted from the glottodrama method ${ }^{28}$ : after preparing the space the participants stand in a large circle; one at a time, each says their name accompanied by a simple gesture of their own invention. The names and gestures are repeated by the group, until by the end, a "choreographic chain" of gestures and names has formed that includes all participants (students, teachers and visitors). The activity culminates in a "dance": the group performs the sequence of gestures together in silence, endeavoring to "flow" choreographically from one gesture to the next until all are complete. Several advantages are immediately apparent: the activity is cognitively challenging (one has to memorize the names and gestures), kinesthetically and sensorily engaging (one has to say the names out loud while physically performing the gestures), and generally amusing, involving much laughter. By the end of our warm-up, the bright eyes, flushed cheeks and relaxed postures of the participants indicated a high level of awareness, sensitization, and readiness to begin the deeper work of the session.

At this point, we asked the international students, whose names everyone now knew, to say where they came from. The rest of the group was then subdivided into three smaller groups: a "team" for each international student. Each international student was then asked to share with their team two of their own "intercultural experiences" - one with U.S.-Americans at UNCA and one with U.S.-Americans at home (France, Germany or Austria, respectively). The

\footnotetext{
${ }^{26}$ Although the course leaders themselves, as experienced performers in the respective languacultural styles, might have served well enough for this purpose, other considerations weighed against this. For one, the simple fact of pre-established teacher-student relationships would tend to contextualize the interaction in ways not representative of "real life." The other significant consideration had to do with "community building" (see footnote 26).

${ }^{27}$ It would have been ideal, of course, to have had "internationals" involved from the beginning and throughout as equal members of a dialogic learning community. While we did what we could to approach this ideal, the fact remained that both the Mayan poet Donny Brito May, who joined us in the first session, and the exchange students who joined us in the final session were "guests." In the semester that followed the one covered in this report, we took pains to involve international students from the very beginning.

${ }^{28}$ For a full description of this method, see Nofri (2014).
} 
team's task was then to develop a brief scenic performance of each experience. About 15 minutes were devoted to this development work. ${ }^{29}$

The six performances that resulted were then presented, one after another, with the full group as audience. After all scenes had been presented, there followed a guided discussion in plenum, which opened with the questions, "What did you notice? What specific cultural differences came into play? How might the misunderstanding or conflict have been better negotiated?" As part of this discussion, the international students had opportunities to ask the U.S.-American students questions and vice versa.

Of particular interest here was the fact that the three international students' experiences foregrounded similar features of U.S.-American languaculture, albeit differently inflected. Both the German student and the Austrian student related experiences involving the typical U.S.-American form of greeting: "Hey, how's it going?" In their scenes, the protagonist is greeted in this manner by an acquaintance, who, instead of then waiting for an answer, simply keeps walking. In one scene, this same encounter was repeated several times in rapid succession with different interlocutors, and the effect was quite humorous. ${ }^{30}$ The workshop participants, moreover, were immediately able to grasp what had "gone wrong," as well as the reasons for it: The German (or Austrian) protagonist had understood two distinct illocutionary acts (a greeting followed by a question), whereas in fact only one such act was intended (a greeting). In the discussion, the specific differences between German and U.S.American languacultures that underlay this misunderstanding became clear: German languacultures tend to place a certain value on directness, and members of those languacultures will therefore generally say what they mean and, conversely, not say anything they don't mean. Hence their culturally-determined tendency to understand the utterance, "How's it going?" as an actual question, in which the speaker is expressing an interest in the addressee's welfare. When in this encounter the U.S.-American speaker does not even break stride, the German or Austrian is confused. They understand the English language perfectly. What they do not understand is the U.S.-American languaculture, which finally determines how the utterance functions in this particular social interaction.

\footnotetext{
${ }^{29}$ While the students themselves would gladly have had more time for this phase, we determined that a more compressed format was desirable not only given the limited amount of time allotted for the workshop itself, but also in the interest of making the performances as spontaneous and unrehearsed as possible: essentially a first "on your feet" run-through of the concept developed in the group.

${ }^{30}$ The function of humor in this context deserves a fuller investigation. For our present purposes, suffice it to say that, apart from increasing the audience's enjoyment of the scene, the humorous repetition, amplification and simplification also allowed the audience to understand the intercultural drama of the scene more clearly and immediately, and to recognize themselves and their own culture in it - without feeling "attacked" or too harshly criticized thereby.
} 
All of this emerged in the discussion. When the German student, who had followed the discussion closely, then asked, "Well, but then how do you know if someone really is interested in how you're doing?" the U.S.-American students were not immediately able to answer. Then someone mentioned body language. The illocutionary function (the actual social meaning) of the grammatical question "How's it going?" is determined by a non-linguistic context: whether or not, for example, the speaker slows their pace or comes to a halt in front of the addressee. ${ }^{31}$

What is of particular interest for our purposes here is that the discussion involved a double reflexivity. The German exchange student learned something about their own languaculture, about U.S.-American languaculture, and about how these two interact in his daily life, thus clarifying (and, one hopes, alleviating) a source of real irritation. For the U.S.-American students as well, the two languacultures and their interactivity were made clear, albeit from the other point of view, thus enabling them both a) to better negotiate these simple social interactions in a future German cultural context and b) to approach German visitors to the U.S. with more finesse, flexibility and empathy. Both parties, one might say, had entered the "third space" of intercultural competence.

The question of empathy is also apropos here, since the development of empathy is one of the distinct features of Intercultural Communicative Competence. It is also one of the distinct advantages of performative work, particularly work involving drama and other forms of roleplay. In other words, the choice to have the participants not merely share their "intercultural experiences" discursively, but to perform them in an embodied way with and for each other seems to have opened a zone for what we might call a fully empathic imagination of the languacultural other. ${ }^{32}$

Moreover, although it was the result of chance, it turned out to be our great good fortune that we had international students from two different German-speaking lands join us. As quickly emerged in the group discussion, their perceptions of U.S.-American languaculture (as well as their self-perceptions) evinced certain subtle differences. (This is to say nothing of their mutual perceptions: how the Germans see the Austrians and vice versa.) This realization opened the discussion to a more fine-grained analysis, to which the French exchange student also contributed. Just as U.S.-Americans, particularly in the South, are quick to point out the cultural differences among various parts of the country, so native speakers of German and

\footnotetext{
${ }^{31}$ One can even note subtle gradations: a slight deceleration or stutter-step might indicate an actual question, but with the expectation that the answer will be brief.

${ }^{32}$ For a fuller discussion of the complex role empathy plays in intercultural communication (and in social meaning-making in general), see Aden (2017).
} 
French turn out to be rather diverse in terms of culture, such that one cannot speak of "German culture" or "French culture" except in the most general (and potentially reductive) terms. As the performances taken together showed, whenever two people meet, the encounter is always an imbrication of personal, familial, communal, regional, and national features, to say nothing of socio-economic, racial, ethnic and religious aspects. Thus when we teach (or when students learn) about culture, there is an imperative for as much specificity as possible: German culture as expressed in the village of Herzogenaurach in the Middle Franconian region of Bavaria; Austrian culture as we find it in modern day Vienna; French culture as we see it in the Parisian suburbs. At most one can speak of languacultural "tendencies"; but in any given encounter, one must be prepared to adjust one's perceptions to the individual human Other.

The questionnaire for the third "Shared Experience" contained the following questions:

1. In your opinion, what was the most valuable aspect of the $3^{\text {rd }}$ "Shared Experience"? Why?

2. How did meeting together with the other language class (FREN 230 or GERM 210) shape your experience this semester?

3. Looking back on all three Shared Experiences: what for you was the most valuable aspect of these encounters? Why?

4. Looking forward: if you were to participate in another semester of Shared Experiences what would you like to see/learn/do as part of these encounters?

The questionnaires and debriefing that followed this final session produced the following data:

\begin{tabular}{|c|c|c|}
\hline Question & Major themes & Representative quotes \\
\hline $\begin{array}{l}\text { 1. In your opinion, what was the } \\
\text { most valuable aspect of the } 3^{\text {rd }} \\
\text { "Shared Experience"? Why? }\end{array}$ & $\begin{array}{l}\text { a. dialogue w/Other } \\
\text { b. practice }\end{array}$ & $\begin{array}{l}\text { "Being able to talk about cultural differences with } \\
\text { exchange students form that culture." } \\
\text { "Actually being able to discuss instances of culture } \\
\text { clashes and seeing how what we have been } \\
\text { learning in the experience is actually put into } \\
\text { practice. It made the shared experience info } \\
\text { authentic." }\end{array}$ \\
\hline $\begin{array}{l}\text { 2. How did meeting together with } \\
\text { the other language class (FREN } \\
230 \text { or GERM 210) shape your } \\
\text { experience this semester? }\end{array}$ & $\begin{array}{l}\text { a. community } \\
\text { b. skepticism }\end{array}$ & $\begin{array}{l}\text { "Creates a bit more community within the study } \\
\text { of languages, as opposed to just the study of a } \\
\text { single language." } \\
\text { "It was nice to meet other people who are also } \\
\text { learning a foreign language." } \\
\text { "I don't think it was fundamental to the } \\
\text { experience." }\end{array}$ \\
\hline
\end{tabular}




\begin{tabular}{|c|c|c|}
\hline & c. diversity of perspectives & $\begin{array}{l}\text { "I don't know how much it actually shaped the } \\
\text { experience, because there weren't many } \\
\text { opportunities to actually interact on the basis of } \\
\text { learning different languages." } \\
\text { "I thought it was very helpful in terms of } \\
\text { understanding different cultural norms. While the } \\
\text { norms are different from in the U.S., it was good } \\
\text { to learn about not only French norms but German } \\
\text { norms too." }\end{array}$ \\
\hline $\begin{array}{l}\text { 3. Looking back on all three } \\
\text { Shared Experiences: what for you } \\
\text { was the most valuable aspect of } \\
\text { these encounters? Why? }\end{array}$ & $\begin{array}{l}\text { a. dialogue w/Other } \\
\text { b. discussion } \\
\text { c. performance } \\
\text { d. community }\end{array}$ & $\begin{array}{l}\text { "Hearing the perspectives of different cultures. I } \\
\text { enjoyed hearing from the professor from Mexico } \\
\text { and speaking with the students from Germany, } \\
\text { France and Austria." } \\
\text { "Being able to talk in groups/discuss cultural } \\
\text { norms and differences and literally sharing } \\
\text { experiences of these differences as well as acting } \\
\text { them out." } \\
\text { "The most valuable aspects of all the encounters, } \\
\text { to me was the debrief and discussion we had." } \\
\text { "The skits were extremely valuable because } \\
\text { seeing the way a different culture acts is better } \\
\text { than just being told about it." } \\
\text { "Get to know people, make friends out of class." }\end{array}$ \\
\hline $\begin{array}{l}\text { 4. Looking forward: if you were to } \\
\text { participate in another semester } \\
\text { of Shared Experiences, what } \\
\text { would you like to see/learn/do as } \\
\text { part of these encounters? }\end{array}$ & $\begin{array}{l}\text { a. dialogue w/Other } \\
\text { b. focus on language } \\
\text { c. performance } \\
\text { d. skepticism }\end{array}$ & $\begin{array}{l}\text { "I would definitely like more meetings with people } \\
\text { not from the U.S." } \\
\text { "It would be great to exercise the spoken } \\
\text { language more." } \\
\text { "Maybe being forced to act as if we were from a } \\
\text { different culture." } \\
\text { "Maybe focus on practicing encountering and } \\
\text { working through culture clash would be really } \\
\text { awesome." } \\
\text { "I would prefer not to have them." }\end{array}$ \\
\hline
\end{tabular}

Table 3: Session 3 participant feedback

Since this final questionnaire covered not only the $3^{\text {rd }}$ Shared Experience but also served as a source of data on the entire Shared Experiences pilot curriculum, I will now attempt to summarize our findings in the form of general take-aways.

\section{General take-aways}

1. As regards the overarching three-part plan of the program, the data tended to confirm its appropriateness. With the help of the activities and materials presented, the students 
naturally moved from awareness of the complexity of culture, of cultural differences and of interculturality to a desire for deeper knowledge and for practical skills. This further suggests that having three distinct sessions (or phases) is a useful formal buttress to the learning process itself, and ought to be embraced in future instantiations of the program.

2. The data on all three sessions, but particularly on the $3^{\text {rd }}$ Shared Experience are unequivocal on the issue of giving students opportunities to interact directly: with each other, with their teachers, and above all with individuals who fully and instinctively embody the values and practices of other cultures, even if these are not necessarily the cultures the students themselves are studying. A second, though less ideal, possibility would be to invite individuals who have extensive experience in other cultures and who themselves possess significant intercultural competence to join the group. Such experience, moreover, is best communicated in some form of storytelling (whether narrated, staged or both).

3. A performative or experiential approach presents significant advantages for intercultural learning, provided it is complemented by sufficient theoretical or discursive context. This context, however, ought to be given post hoc, i.e. after the experience itself, and can usefully be arrived at "inductively" through discussion. Moreover, students place a high value on the opportunity to share and compare experiences and reflections with each other (see \#1 above).

4. Not every student will be "on board" from the start, and for various reasons, not all of which can be predicted or alleviated. But a concerted effort must be made to explain and to some extent justify the program as transparently as possible. It seems to us in retrospect that several possible arguments can be made in this regard:

a. the institutional argument: the advantages of creating a community among foreign language teachers and learners and foreign students in a given institutional context.

b. the pedagogical argument: the proven effectiveness of experiential and performative approaches especially in the field of FL teaching and learning and in intercultural education.

c. the theoretical argument: the complex imbrication of language and culture ("languaculture").

d. the ethical argument: interculturality and ICC as rooted in/fundamental to the general value system of humanistic education, which aims at global citizenship. 
e. the political argument: "slow/deep" learning as a necessary resistance to the neoliberal emphasis on "efficiency," "maximization of human capital," etc., that is: to the commodification of education.

f. the practical argument: the complex of awareness/attitudes, knowledges and skills that form ICC are indispensable for success (however defined) in an increasingly intercultural world.

These are mere hints at possible justifications. Certainly there are others. (Depending on the institutional context and the particular group of participants, it might be most effective to combine two or more.) Thinking through and articulating these arguments for oneself is well worth the effort, however: not only in order to dissolve, to whatever degree possible, the skeptical student's resistance, but also in order to prepare oneself for the inevitable challenge by policymakers, by administrators and even by colleagues as to the usefulness of such performative work in intercultural education.

\section{Lingering questions}

The pilot program in Shared Experiences produced a number of intriguing and, in some cases, troubling questions. Some of these questions could by all rights have been anticipated and perhaps answered beforehand, but the institutional circumstances (an admittedly rather vague departmental mandate combined with little time to plan and prepare) meant that we simply had to proceed as best we could while trying to remain as flexible as possible. (As mentioned above, this need for flexibility and adaptability was one reason for soliciting student feedback along the way, i.e. after each session.)

Among the questions that seem most urgently to require answers are:

1. Assessment. How might the effectiveness of our performative approach to teaching intercultural competence (as we have defined it here) be better assessed and made institutionally "visible"? Are assessment tools already available that are particularly well-adapted to this area, or would they need to be developed? To put a fine point on it: how should an individual student's participation in the Shared Experiences be assessed, if at all, in terms of their grade?

2. Theory and Praxis. How can the Shared Experiences themselves (or similar curricula) be both deepened and made more intellectually available to participants? In other words: what is the ideal proportion of theory to praxis? To what degree does (or should) institutional context play into this calculus?

3. Creativity. How can the student's creativity and creative imagination be more fully engaged in the service of intercultural education? 
4. Emotions. How can the inherent "volatility" and hence potential "danger" of experiential/performative work - which of course is a function of its holistic quality - be better managed? What is the best practice when it comes to students who feel disproportionately anxious or threatened by the modes of presence required for performance? ${ }^{33}$

5. The Teacher. What is the role (what are the roles) of the course leaders? How can they strengthen their own competence in teaching ICC? (Professional workshops in intercultural communication? Professional workshops in acting or other modes of performance?)

6. Humor. What is the function of humor in this context? When is laughter a sign of healthy self-recognition and a suspension of ethical judgement, and when is it derisive and condescending? How does laughter interact with current notions of political correctness, especially where these notions touch on cultural differences (for example, gender-roles or the concept of gender itself)?

It is safe to assume that the answers to these and other questions will be context-specific and hence only ever provisional. But to be alert to them as areas that require attention when doing performative intercultural work will perhaps put one in a better position to improvise an answer in the heat of the moment.

\section{Bibliography}

Aden, J. (2017). Developing empathy through theatre: A transcultural perspective. In J. Crutchfield \&

M. Schewe (Eds.), Going performative in intercultural education: International contexts, theoretical perspectives and models of practice (pp. 59-81). Multilingual Matters.

Agar, M. (1995). Language shock: Understanding the culture of conversation. William Morrow.

Byram, M. (2012). Conceptualizing intercultural (communicative) competence and intercultural citizenship. In J. Jackson (Ed.), The Routledge handbook of language and intercultural communication (pp. 85-97). Routledge.

Byram, M. (1997). Teaching and assessing intercultural communicative competence. Multilingual Matters.

\footnotetext{
${ }^{33}$ The form of social anxiety we are alluding to here is, unfortunately, no longer a rare phenomenon among young people in the U.S. According to the American College Health Association's "National College Health Assessment" for the fall semester of 2019, 29.3\% of all undergraduates surveyed reported "Anxiety" as an impediment to their academic performance (https://www.acha.org/NCHA/ACHANCHA Data/Publications and Reports/NCHA/Data/Reports ACHA-NCHAlll.aspx)
} 
Crutchfield, J., \& Schewe, M. (Eds.). (2017). Going performative in intercultural education: International contexts, theoretical perspectives and models of practice. Multilingual Matters. https://doi.org/10.21832/9781783098552

Crutchfield, J. (2015). Fear and trembling: The role of 'negative' emotions in the experience of performance. Scenario, 9(2), 101-114. https://doi.org/10.33178/scenario.9.2.7

Crutchfield, J. (2018). Brief encounters: A workshop on the performative integration of creative writing in the classroom. In M. Fleiner \& O. Mentz (Eds.), The arts in language teaching. International perspectives: performative - aesthetic - transversal (pp. 42-74). LIT Verlag.

Fantini, A. E. (2012). Multiple strategies for assessing intercultural communicative competence. In J. Jackson (Ed.), The Routledge Handbook of language and intercultural communication (pp. 390405). Routledge.

Fantini, A. E. (2009). Developing intercultural competencies: An educational imperative for the 20th century. Studies in Language and Literature, 28(2), 192-213.

Hall, E. T. (1976). Beyond Culture. Anchor Books.

Hofstede, G. J. (2002). Exploring culture: Exercises, stories and synthetic cultures. Intercultural Press.

Kiefer, M., Sim, E.-J., Liebich, S., Hauk, O., \& Tanaka, J. (2007). Experience-dependent plasticity of conceptual representations in human sensory-motor areas. Journal of Cognitive Neuroscience, 19(3), 525-542. https://doi.org/10.1162/jocn.2007.19.3.525

Kumaravadivelu, B. (2006). Understanding Language Teaching: From Method to Postmethod. Lawrence Erlbaum Associates. https://doi.org/10.4324/9781410615725

Miladinović, D. (2019). Prinzipien eines performativen Fremdsprachenunterrichts. In S. Even, D. Miladinović \& B. Schmenk (Eds.), Lernbewegungen inszenieren: Performative Zugänge in der Sprach-, Literatur- und Kulturdidaktik. Festschrift für Manfred Schewe zum 65. Geburtstag (pp. 722). Narr Francke Attempto Verlag.

Nofri, C. (2014). The Glottodrama Method: An overview. In C. Nofri \& M. Stracci (Eds.), Performing Arts in Language Learning (pp. 190-199). Edizioni Novaculture.

Risager, K. (2006). Language and culture: Global flows and local complexity. Multilingual Matters. https://doi.org/10.21832/9781853598609

Sambanis, M. (2013). Fremdsprachenunterricht und Neurowissenschaften. Narr.

Schewe, M. (2013). Taking stock and looking ahead: Drama pedagogy as a gateway to a performative teaching and learning culture. Scenario, 7(1), 5-32. https://doi.org/10.33178/scenario.7.1.2

Weaver, G. (1986). Understanding and coping with cross-cultural adjustment stress. In R. M. Paige (Ed.), Cross-cultural orientation: New conceptualizations and applications. University Press of America.

Witte, A., \& Harden, T. (Eds.). (2011). Intercultural competence: Concepts, challenges, evaluations. Peter Lang. https://doi.org/10.3726/978-3-0353-0202-8 
Crutchfield: Shared Experiences

The author wishes to thank the students, colleagues and guests who participated in the Shared Experiences pilot program, especially Lorrie Jayne, Ellen Bailey, Donny Brito May, Juan SanchezMartinez, Michelle Battencourt and Elena Adell. Special thanks are also due to the two anonymous peer reviewers of this article for their insightful criticisms and suggestions for revision. 